\title{
Auditory Feedback and Song Production Do Not Regulate Seasonal Growth of Song Control Circuits in Adult White-Crowned Sparrows
}

\author{
Eliot A. Brenowitz, ${ }^{1,2,4}$ Karin Lent, ${ }^{1}$ and Edwin W. Rubel ${ }^{3,4}$ \\ Departments of ${ }^{1}$ Psychology, ${ }^{2}$ Biology, and ${ }^{3}$ Otolaryngology, and ${ }^{4}$ The Virginia Merrill Bloedel Hearing Research Center, University of Washington, Seattle, \\ Washington 98195-1525
}

\begin{abstract}
An important area of research in neuroscience is understanding what properties of brain structure and function are stimulated by sensory experience and behavioral performance. We tested the roles of experience and behavior in seasonal plasticity of the neural circuits that regulate learned song behavior in adult songbirds. Neurons in these circuits receive auditory input and show selective auditory responses to conspecific song. We asked whether auditory input or song production contribute to seasonal growth of telencephalic song nuclei. Adult male Gambel's white-crowned sparrows were surgically deafened, which eliminates auditory input and greatly reduces song production. These birds were then exposed to photoperiod and hormonal conditions that regulate the growth of song nuclei. We measured the volumes of the nuclei HVC, robust nucleus of arcopallium (RA), and area X at 7 and $30 \mathrm{~d}$ after exposure to long days plus testosterone in deafened and normally hearing birds. We also assessed song production and examined protein kinase $\mathrm{C}$ ( $\mathrm{PKC}$ ) expression because previous research reported that immunostaining for PKC increases transiently after deafening. Deafening did not delay or block the growth of the song nuclei to their full breeding-condition size. PKC activity in RA was not altered by deafening in the sparrows. Song continued to be well structured for up to 10 months after deafening, but song production decreased almost eightfold. These results suggest that neither auditory input nor high rates of song production are necessary for seasonal growth of the adult song control system in this species.
\end{abstract}

Key words: seasonal; plasticity; auditory; birdsong; testosterone; bird

\section{Introduction}

An important issue in neuroscience is whether structural changes in the brain are related to sensory experience or performance of learned behavior. Examples include changes in dendritic structure (Greenough et al., 1987), neurogenesis in the mammalian olfactory bulb and dentate gyrus (Ming and Song, 2005) and in the avian hippocampus (Barnea and Nottebohm, 1994) and song system (Li et al., 2000), and seasonal plasticity of the avian song system (Brenowitz, 2004). The nature of the cause and effect relationship between these factors, however, may not always be clear (Leuner et al., 2006).

We used seasonal plasticity of the avian song system to examine the contributions of experience and behavior to structural changes in the brain. The nuclei that control song learning and production in birds show pronounced seasonal plasticity in volume and neuronal attributes (for review, see Brenowitz, 2004).

Received March 20, 2007; revised May 7, 2007; accepted May 20, 2007.

This work was supported by National Institutes of Health Grants MH53032, DC03829, and DC04661. We thank Mark Konishi for advice on cochlear removal in white-crowned sparrows, Sarah Woolley and Erich Jarvis for providing unpublished information on the effects of deafening on song rate in other bird species, David Perkel for valuable suggestions on this manuscript, and John Meitzen for persistence.

Correspondence should be addressed to Eliot A. Brenowitz, Department of Psychology, Box 351525, University of Washington, Seattle, WA 98195-1525. E-mail: eliotb@u.washington.edu.

DOI:10.1523/JNEUROSCI.1248-07.2007

Copyright $\odot 2007$ Society for Neuroscience $\quad$ 0270-6474/07/276810-05\$15.00/0
We asked whether auditory stimulation contributes to the seasonal growth of the song nuclei. HVC receives input from forebrain auditory regions and projects to the robust nucleus of arcopallium (RA) and area X (supplemental Fig. 1, available at www.jneurosci.org as supplemental material). There are several reasons for hypothesizing a role for auditory input: (1) neurons in several song nuclei show auditory responses to song stimuli in awake and/or anesthetized or sleeping birds, with pronounced selectivity for a bird's own song (for review, see Theunissen et al., 2004); (2) vocalizations are important in coordinating the timing of reproduction in birds (for review, see Cheng and Durand, 2004); (3) auditory feedback is necessary for the juvenile development of song, and its adult maintenance in some species (for review, see Woolley, 2004); (4) auditory information modifies expression of several activity-dependent genes (e.g., ZENK, c-fos, Arc) in telencephalic auditory regions and the song nuclei (for review, see Mello et al., 2004); and (5) auditory input increases CREB phosphorylation in HVC neurons and immunostaining for protein kinase $\mathrm{C}$ (PKC) in RA of zebra finches and Bengalese finches (Sakaguchi and Yamaguchi, 1997; Sakaguchi et al., 1999; Watanabe et al., 2002).

Deafened birds sing at lower rates than hearing birds (Jarvis and Nottebohm, 1997) (S. M. N. Woolley and E. W. Rubel, unpublished observation) and this allowed us to also test the hypothesis that seasonal growth of the song nuclei is the conse- 
quence of high rates of singing (Ball et al., 2002; Sartor et al., 2002; Sartor and Ball, 2005). This model posits that increased circulating testosterone $(\mathrm{T})$ during breeding stimulates singing which, in turn, induces nuclear growth by increasing the synthesis of brainderived neurotrophic factor. BDNF increases neuronal recruitment in HVC (Li et al., 2000).

We found that the loss of auditory input and decreased song production in deafened adult Gambel's white-crowned sparrows (GWCSs) did not block or delay seasonal-like growth of song nuclei.

\section{Materials and Methods}

Collection and housing of birds. We collected male GWCSs during their autumnal migration. Nineteen males were housed for 12 weeks on short days (sds; $8 \mathrm{~h}$ light) to mimic their nonbreeding photoperiod and ensure they were sensitive to the stimulatory effects of breeding photoperiod and elevated T. GWCSs kept on sds indefinitely maintain regressed testes, basal or nondetectable levels of circulating $\mathrm{T}$, and regressed song nuclei (for review, see Brenowitz, 2004). All birds were 1-2 years old during the study and age balanced across groups.

Surgical procedure. Eleven birds were anesthetized with isoflurane and deafened by removing both cochleae from the inner ears (Konishi, 1963; Woolley and Rubel, 1997). We punctured the tympanic membrane, removed the underlying columella, and inserted a wire hook into the oval window. The hook was manipulated to seize the basal end of the basilar papilla (cochlea), which was removed entirely. We confirmed successful and complete removal of the intact cochlea by floating the excised tissue in water and examining it under a dissecting microscope. Cochlear removal results in immediate cessation of all acoustically driven and spontaneous extracellular action potential activity in the auditory nerve and nucleus magnocellularis of the auditory brainstem (Born et al., 1991). Sham surgeries in which the tympanic membrane was exposed but not punctured were performed on eight additional birds.

One week after the surgery, all birds were photoshifted overnight from sds to breeding-typical long days (lds; $20 \mathrm{~h}$ light). We also then implanted each bird with a SILASTIC capsule $(1.47 \mathrm{~mm}$ inner diameter $\times 1.96 \mathrm{~mm}$ outer diameter) containing $12 \mathrm{~mm}$ of crystalline $\mathrm{T}$ to rapidly elevate plasma concentrations. This sized implant in GWCSs produces circulating T levels of 7-12 ng/ml (Smith et al., 1997), which corresponds well with levels in wild breeding birds $(\sim 4-12 \mathrm{ng} / \mathrm{ml}$ ) (Wingfield and Farner, 1978). Without these implants, captive males do not achieve breeding $T$ levels (Wingfield and Moore, 1987). HVC, RA, and X express androgen receptor protein or mRNA. Seasonal growth of the song nuclei occurs rapidly and sequentially (Tramontin et al., 2000). Within $7 \mathrm{~d}$ of exposure to ld and enhanced T levels, HVC in GWCSs adds $\sim 50,000$ neurons and increases its volume to $\sim 94 \%$ of its maximal size. RA and X grow more slowly, reaching their maximal size after $\sim 20 \mathrm{~d}$. Six of the deafened birds were therefore killed after $7 \mathrm{~d}$ of ld plus $\mathrm{T}$. The remaining five deafened birds were killed after $30 \mathrm{~d}$. Four of the sham-operated (hearing) birds were killed after $7 \mathrm{~d}$, and the other four at $30 \mathrm{~d}$. Two survival times were used to determine whether deafening prevents or delays the time course of growth of the song nuclei.

Song behavior. We measured song production in all five of the $30 \mathrm{~d}$ deafened and three of the four $30 \mathrm{~d}$ hearing birds. Song was recorded from each bird for $45 \mathrm{~min}$ on each of $10 \mathrm{~d}$ over days 2-22 after initial ld plus T exposure; Tramontin et al. (2000) showed that HVC, RA, and X were fully grown after $20 \mathrm{~d}$ of ld plus T in hearing GWCSs. The time and order of recording each day was randomized between groups. The number of songs produced by each bird during each 45 min recording session was counted.

Sonograms of all songs were visually inspected by computer (Syrinx; J. Burt, University of Washington, Seattle, WA). We did not, however, quantitatively analyze song structure because both viewing sonograms and listening to songs suggested that song quality did not degrade in deafened birds even after 10 months.

Histology and brain morphometry. Birds were anesthetized and perfused with saline followed by $4 \%$ paraformaldehyde in $0.1 \mathrm{M} \mathrm{PBS,} \mathrm{pH} 7.0$, at $4^{\circ} \mathrm{C}$. Brains were processed for sectioning at $40 \mu \mathrm{m}$ on a freezing microtome. Every third section was mounted and stained with thionin. Using standard methods (Tramontin et al., 1998), we measured the volumes of HVC, RA, and X, the three telencephalic song nuclei that undergo pronounced seasonal changes in size. All brain measurements were made blind to treatment group. To control for possible individual differences in overall brain size and/or histological preparation, statistical analyses were conducted on the volumes of each nucleus divided by the volume of the entire telencephalon. We estimated the volume of the telencephalon as described previously (Tramontin et al., 2000).

Immunostaining for PKC. Immunostaining for PKC in RA of zebra finches and Bengalese finches increased transiently after deafening (Sakaguchi and Yamaguchi, 1997; Watanabe et al., 2002). To determine whether PKC activity increased in deafened GWCSs, we immunostained sections throughout RA from birds in the 7 and $30 \mathrm{~d}$ deafened and $30 \mathrm{~d}$ hearing groups. We did not analyze PKC activity in RA of the $7 \mathrm{~d}$ hearing group because previous measurements showed that the other three groups did not differ (see Results) over a time period when PKC is elevated in deafened finches (Watanabe et al., 2002). We followed the methods of Watanabe et al. (2002), using a primary antibody for PKC $\beta 1$ (SC-209; Santa Cruz Biotechnology, Santa Cruz, CA) and the Vectastain $\mathrm{ABC}$ kit (Vector Laboratories, Burlingame, $\mathrm{CA}$ ). Control sections without primary antibody were processed in parallel and did not show any specific reaction product.

We used optical densitometry to quantify immunostaining for PKC. We measured pixel density in sections where the immunoreaction product was dark enough to distinguish the borders of RA ( $n=7-10$ sections per bird) using a constant illumination level. Pixel density values were calibrated to a Kodak (Rochester, NY) step tablet and the standards were fitted to a Rodbard curve $\left(r^{2}=0.9979\right)$ in Object Image (version 2.08). We measured pixel density over the entire area of RA in each sampled section. To independently assess effects of deafening on PKC activity, we also measured pixel density over an equal-sized area of the arcopallium outside RA. This region receives input from several telencephalic auditory regions (Mello et al., 1998). The pixel densities were averaged to obtain a single value for each region for each bird.

Hormone assay. The plasma concentrations of $\mathrm{T}$ at the time of killing were measured for the 7 and $30 \mathrm{~d}$ deafened and $30 \mathrm{~d}$ sham groups. We did not measure $\mathrm{T}$ concentrations in the $7 \mathrm{~d}$ sham group because previous analysis showed there to be no significant differences between the other three groups (see Results), as expected given that all birds received the same size T implant and photoperiod. We used standard methods to collect blood, harvest plasma, and measure circulating $\mathrm{T}$ by radioimmunoassay (Tramontin et al., 2001).

Statistical analyses. The median numbers of songs for each $45 \mathrm{~min}$ recording session on each of the 10 sampling days were compared between the $30 \mathrm{~d}$ deafened and hearing groups with a Mann-Whitney rank sum test.

The volumes of HVC, RA, and X, divided by the volume of the telencephalon, were compared between the four treatment groups with separate one-way ANOVAs for each nucleus, with treatment as the independent factor. The ANOVAs were followed by post hoc pairwise comparisons using the Student-Neuman-Keuls test.

For PKC immunostaining, pixel density over RA was compared between the four treatment groups using one-way ANOVAs. We used a Kruskal-Wallis one-way ANOVA on Ranks to test for changes in pixel density over the arcopallium because these data were not normally distributed.

Plasma T concentrations were compared between groups with oneway ANOVAs and the $\alpha$ level for all tests was 0.05 .

\section{Results}

\section{Song behavior}

Deafened birds sang much less than did the hearing birds. Birds in both the $30 \mathrm{~d}$ deafened and hearing groups began to sing within $3 \mathrm{~d}$ of their initial exposure to ld plus T. However, the median rate of song production observed in the deafened birds was 5.7 songs per $45 \mathrm{~min}$ (quartile range, 1.7-15.8), whereas the median rate in 
Table 1. Brain morphometry and circulating testosterone levels ( $x \pm$ SEM)

\begin{tabular}{|c|c|c|c|c|c|c|c|}
\hline & sd & 7 d deaf & $7 \mathrm{~d}$ hearing & 30 d deaf & 30 d hearing & $F_{\mathrm{df}}$ & $p$ \\
\hline \multicolumn{8}{|l|}{ HVC/telencephalon } \\
\hline$\left(\times 10^{-3}\right)$ & $0.93+0.08^{a}$ & $1.76 \pm 0.09^{b}$ & $1.86 \pm 0.04^{b}$ & $2.49 \pm 0.09^{b, c}$ & $2.41 \pm 0.33^{c}$ & $19.4_{4,23}$ & $<0.001$ \\
\hline \multicolumn{8}{|l|}{ RA/telencephalon } \\
\hline$\left(\times 0^{-4}\right)$ & $5.68 \pm 0.66^{a}$ & $7.86 \pm 0.91^{a b}$ & $7.99 \pm 0.24^{a b}$ & $11.5 \pm 1.08^{b, c}$ & $9.76 \pm 0.65^{c}$ & $7.1_{4,23}$ & 0.001 \\
\hline \multicolumn{8}{|l|}{ X/telencephalon } \\
\hline$\left(\times 10^{-3}\right)$ & $2.43 \pm 0.31^{a}$ & $4.35 \pm 0.36^{b}$ & $4.14 \pm 0.32^{b}$ & $6.27 \pm 0.18^{c}$ & $5.49 \pm 0.46^{c}$ & $19.6_{4,23}$ & $<0.001$ \\
\hline \multicolumn{8}{|l|}{ Telencephalon } \\
\hline$\left(\mathrm{mm}^{3}\right)$ & $596.2 \pm 16.3$ & $547.7 \pm 57.9$ & $534.1 \pm 30.2$ & $590 \pm 18.0$ & $539.5 \pm 76.2$ & $0.40_{4,23}$ & 0.803 \\
\hline Testosterone (ng/ml) & $0.04 \pm 0.01^{a}$ & $12.9 \pm 1.6^{b}$ & $\mathrm{~N} / \mathrm{A}$ & $8.4 \pm 0.6^{c}$ & $9.6 \pm 1.6^{b_{c}^{c}}$ & $25.3_{3,18}^{4,20}$ & $<0.001$ \\
\hline
\end{tabular}

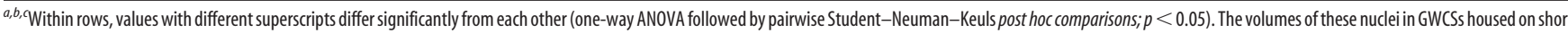
days with regressed song systems from the study by Tramontin et al. (2000) are also shown to demonstrate that seasonal-like growth occurred in each of the 7 and $30 \mathrm{~d}$ deaf and hearing groups. The sd birds were housed under the same conditions as the birds in the present study, before surgery and the shift to ld + T. N/A, Data not collected.

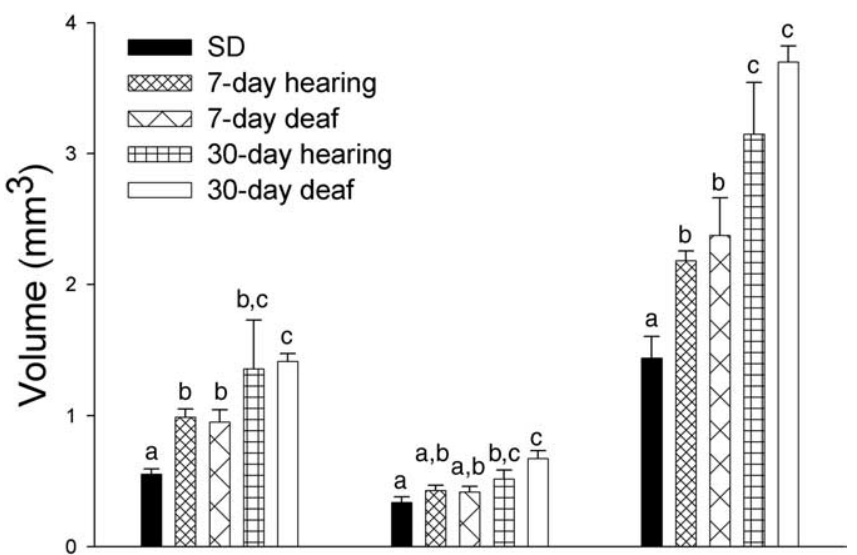

Figure 1. The absolute volumes ( $x \pm$ SEM) of HVC, RA, and $X$ in the four treatment groups. Different letters above bars indicate significant differences in volume between the treatment groups for each nucleus.

hearing birds was 40.4 songs per 45 min (range, 16.5-109.3) (rank sum, $t=65 ; n=10 ; p=0.003$ ).

Although the deaf birds sang less often, there did not appear to be any degradation in song structure (supplemental Fig. 2, available at www.jneurosci.org as supplemental material), even in one bird observed for 10 months after deafening. Deafened birds continued to produce well structured songs when exposed to a breeding photoperiod for as long as they were observed.

\section{Brain morphometry}

Deafening did not disrupt the growth of HVC, RA, and X. The volumes of these nuclei did not differ between deafened and hearing birds at either the 7 or $30 \mathrm{~d}$ survival times (Table 1, Fig. 1). All three nuclei in the experimental groups were significantly larger than in SD birds. Also, all three nuclei were significantly larger in the $30 \mathrm{~d}$ deafened birds than in either $7 \mathrm{~d}$ group, the relative volume of HVC was larger in the $30 \mathrm{~d}$ hearing birds than the $7 \mathrm{~d}$ deafened birds, and the absolute volume of $\mathrm{X}$ was larger in the $30 \mathrm{~d}$ hearing birds than the $7 \mathrm{~d}$ hearing birds (Table 1, Fig. 1).

Telencephalon volume did not differ significantly among treatment groups (Table 1).

\section{Immunostaining for PKC}

Deafening did not alter PKC activity in RA in either the $7 \mathrm{~d}$ or $30 \mathrm{~d}$ deafened groups relative to the $30 \mathrm{~d}$ hearing birds (Fig. 2, Table 2 ). PKC activity was, however, significantly lower in the arcopallium of the $30 \mathrm{~d}$ deafened birds relative to $30 \mathrm{~d}$ hearing birds ( post hoc Dunn's test, $Q=4.66, p<0.05$ ).
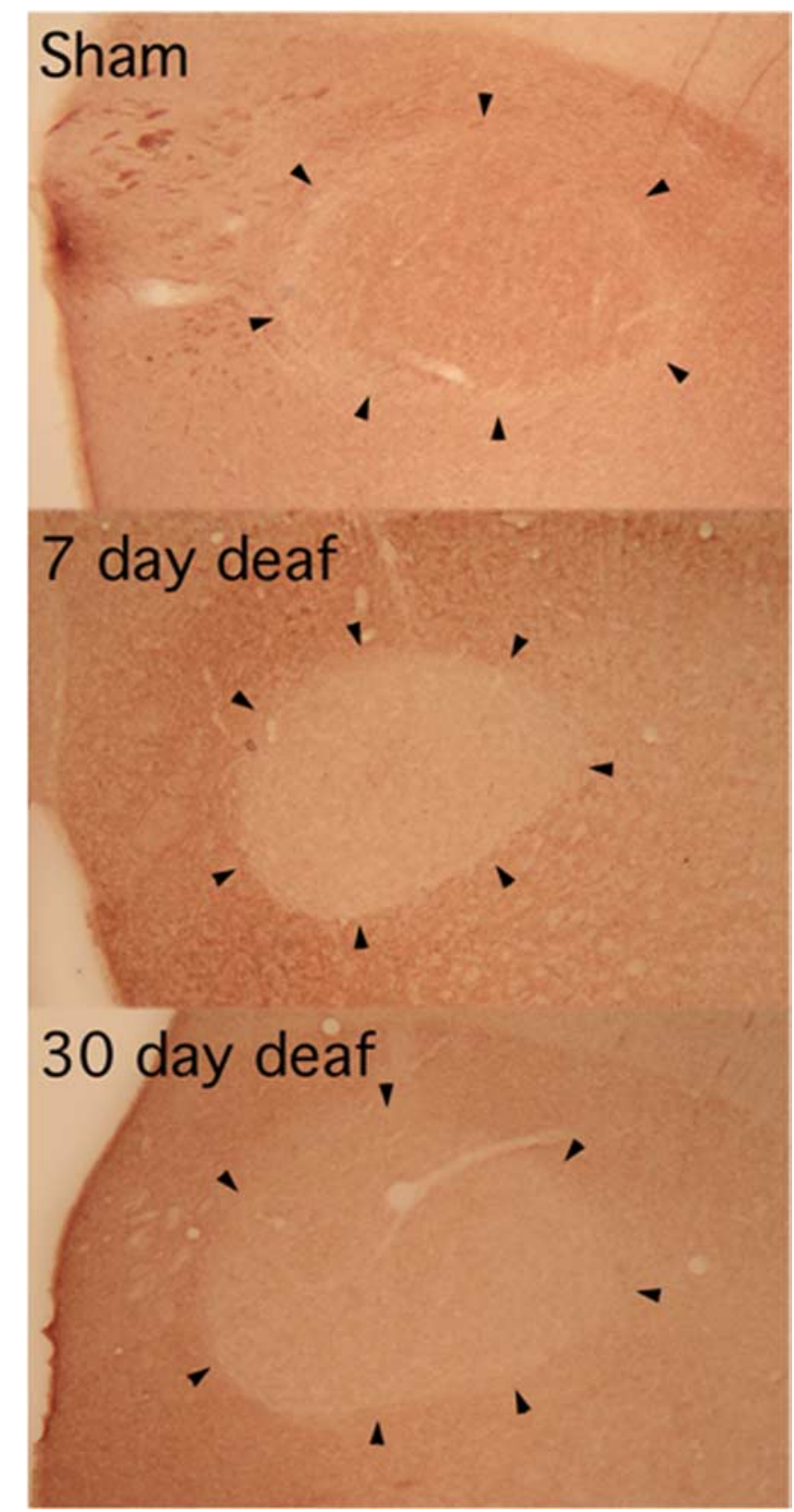

Figure 2. Representative sections containing RA (arrowheads) and surrounding auditory recipient arcopallium immunostained for PKC activity in hearing (top), $7 \mathrm{~d}$ deaf (middle), and $30 \mathrm{~d}$ deaf (bottom) treatment groups. Optical density measurements indicated that PKC staining in RA did not differ between the three groups, whereas in arcopallium it was lower in the $30 \mathrm{~d}$ deaf than in hearing birds (see Results). 
Table 2. Pixel density measurements of protein kinase C immunostaining in RA ( $x \pm$ SEM) and adjacent arcopallium (median, quartile range)

\begin{tabular}{|c|c|c|c|c|c|}
\hline & $7 \mathrm{~d}$ deaf & 30 d deaf & $30 \mathrm{~d}$ hearing & Test statistic & $p$ \\
\hline $\mathrm{RA}$ & $0.67 \pm 0.08$ & $0.62 \pm 0.04$ & $0.68 \pm 0.03$ & $F=1.18_{2,9}$ & 0.362 \\
\hline Arcopallium & $0.67(0.61-0.72)$ & $0.56(0.53-0.58)$ & $0.62(0.60-0.70)$ & $H=36.07_{2}$ & $<0.001$ \\
\hline
\end{tabular}

\section{Hormone assay}

Plasma T concentration was greater in the deafened and hearing ld plus T groups than in sd GWCSs (Table 1). T levels were significantly higher in the $7 \mathrm{~d}$ deafened birds than in the $30 \mathrm{~d}$ deafened group, but did not differ significantly between the $7 \mathrm{~d}$ deafened and $30 \mathrm{~d}$ hearing or the two $30 \mathrm{~d}$ groups (Table 1). In all ld plus $\mathrm{T}$ groups, $\mathrm{T}$ concentrations were within the breeding physiological range (Wingfield and Farner, 1978).

\section{Discussion}

A principal finding is that seasonal-like growth of the song nuclei in adult GWCSs does not require auditory activity. In both survival groups, there was no significant difference in nuclear volumes between hearing and deafened birds. The larger nuclei in the $30 \mathrm{~d}$ deafened than the $7 \mathrm{~d}$ deafened birds might suggest that deafening delayed the growth of the song system. The nuclei in the $30 \mathrm{~d}$ deafened birds were also larger than those in the $7 \mathrm{~d}$ hearing group, however, which argues against this interpretation. We suggest that the greater volumes in the $30 \mathrm{~d}$ deafened birds resulted instead from some additional growth of the nuclei between 7 and $30 \mathrm{~d}$, and this small additional growth achieved significance because of the lower variance in the $30 \mathrm{~d}$ deafened birds compared with the $30 \mathrm{~d}$ hearing group (Table 1, Fig. 1).

The growth of adult song nuclei in the absence of auditory input is consistent with a developmental study by Burek et al. (1991). They deafened male zebra finches at $10 \mathrm{~d}$ posthatch and compared the volumes of HVC, RA, and X in deafened and hearing birds killed between 25 and 120 d of age. Deafening did not delay or prevent the full growth of these nuclei.

A second important result from our study is that seasonal-like growth of the song nuclei is independent of the rate at which birds sing. Hearing GWCSs sang nearly eight times more often than deafened birds. Deafened Bengalese finches, zebra finches, and canaries also sing less than hearing birds (Jarvis and Nottebohm, 1997). Despite the pronounced difference in song rate between deafened and hearing GWCSs, the size of the nuclei did not differ. This suggests that in GWCSs, seasonal-like growth of adult nuclei is not primarily driven by trophic effects associated with song performance. Our study therefore does not support the model proposed by Ball and colleagues (Ball et al., 2002; Sartor and Ball, 2005). This may reflect a species difference in the relative weighting of factors that influence seasonal growth of the song system. It would be interesting to observe the effects of deafening on song production and growth of the song nuclei in starlings.

The observations that deafened and hearing GWCSs differed in auditory input and song production, did not differ in photoperiod or circulating T levels, and their nuclear volumes did not differ are consistent with an alternative model in which seasonal growth of their song system is primarily regulated by increased plasma levels of $\mathrm{T}$ and its metabolites in the breeding season. This model is supported by several studies of GWCSs and song sparrows (for review, see Brenowitz, 2004). For example, implanting $\mathrm{T}$ intracerebrally near HVC in sd GWCSs induces growth of HVC, RA, and X, despite the lack of song production (Brenowitz and Lent, 2002). Additional support for a primary role of $\mathrm{T}$ and its metabolites comes from a study by Alvarez-Borda and Notte- bohm (2002). They compared neuronal recruitment to HVC in gonadally intact and castrated adult nonbreeding male canaries. When matched for song rate, the gonadally intact birds had four times as many new RA-projecting neurons in HVC as did the castrates. This suggests that the contribution of T to HVC neuronal recruitment is greater than that of song production. Much of the seasonal growth of HVC results from an increase in neuron number (for review, see Brenowitz, 2004). These studies together suggest that growth of song nuclei in hearing GWCSs is primarily regulated by $\mathrm{T}$ and its metabolites, with song production and/or auditory input playing a secondary, if any, role.

Song production is strongly influenced by steroid hormones (for review, see Harding, 2004), and deafening might reduce song by depressing hormone levels. This is unlikely for our study, however, because the rate of T release from the SILASTIC implants would be independent of auditory input, and plasma T levels did not differ between the $30 \mathrm{~d}$ deafened and hearing birds (Table 1). Also, chemical deafening of Bengalese finches did not alter endogenous $\mathrm{T}$ levels compared with untreated controls (Woolley and Rubel, 2002). An alternative explanation is that, in the absence of auditory input from self-song and the vocalizations of other birds, males were less motivated to sing.

Deafening decreased the song rate, but song structure apparently did not degrade, even after 10 months. This is consistent with Konishi's (1965) report that a GWCS deafened after it crystallized song continued to produce well structured song for up to three years. The prolonged maintenance of song structure in deafened adult GWCS differs from the decay in song structure over periods of weeks to months after deafening seen in Bengalese finches and zebra finches (Nordeen and Nordeen, 1992; Woolley and Rubel, 1997, 1999, 2002). Because our birds were 1- to 2-year-old, it is unlikely that song maintenance after deafening was caused by age; the effects of deafening on song in zebra finches are less pronounced in older adults (2-6 years) than in younger birds (Lombardino and Nottebohm, 2000). This difference in the importance of auditory feedback between adult GWCS and finches presents an interesting opportunity for comparative study of the genetic and physiological mechanisms of the maintenance of learned song in adult birds.

PKC staining in GWCS RA was not affected by deafening. This result differs from the transient increase in PKC activity in RA of both zebra finches and Bengalese finches after deafening (Sakaguchi and Yamaguchi, 1997; Watanabe et al., 2002). PKC activity increased in RA of the finches at the time when song structure most rapidly degraded in structure, and subsequently decreased once the finches' degraded songs stabilized in structure. Given the presumed role(s) of PKC in some forms of synaptic plasticity (Routtenberg, 1986), Sakaguchi et al. (1999) interpreted the temporary increase in PKC activity as reflecting a period of neural plasticity that is functionally associated with changes in song structure. Because the GWCSs showed no evident change in song structure, our failure to observe an increase in PKC activity is consistent with this hypothesis. The decrease in PKC activity in the auditory recipient arcopallium confirms the success of deafening and the specificity of activity retained in RA. 
Our results are relevant to the broader issue of whether structural changes in the brain are driven by sensory experience and/or behavioral performance. In GWCSs, growth of the song nuclei clearly does not require auditory experience or high levels of song production. In other models, there is conflicting evidence. For example, different studies show that engaging in hippocampaldependent learning tasks either increases, decreases, or does not alter the number of new neurons in the hippocampus (for review, see Leuner et al., 2006). This literature suggests that these hypotheses, although appealing, are challenging to test experimentally. Furthermore, one can question the implicit assumption that experience and behavior can be meaningfully dissociated from activity in their underlying neural and molecular substrates (Born and Rubel, 1988).

\section{References}

Alvarez-Borda B, Nottebohm F (2002) Gonads and singing play separate, additive roles in new neuron recruitment in adult canary brain. J Neurosci 22:8684-8690.

Ball GF, Riters LV, Balthazart J (2002) Neuroendocrinology of song behavior and avian brain plasticity: multiple sites of action of sex steroid hormones. Front Neuroendocrinol 23:137-178.

Barnea A, Nottebohm F (1994) Seasonal recruitment of hippocampal neurons in adult free-ranging black-capped chickadees. Proc Natl Acad Sci USA 91:11217-11221.

Born DE, Rubel EW (1988) Afferent influences on brainstem auditory nuclei of the chicken: presynaptic action potentials regulate protein synthesis in nucleus magnocellularis neurons. J Neurosci 8:901-919.

Born DE, Durham D, Rubel EW (1991) Afferent influences on brainstem auditory nuclei of the chick: nucleus magnocellularis neuronal activity following cochlea removal. Brain Res 557:37-47.

Brenowitz EA (2004) Plasticity of the adult avian song control system. Ann NY Acad Sci 1016:560-585.

Brenowitz EA, Lent K (2002) Act locally and think globally: intracerebral testosterone implants induce seasonal-like growth of adult avian song control circuits. Proc Natl Acad Sci USA 99:12421-12426.

Burek MJ, Nordeen KW, Nordeen EJ (1991) Neuron loss and addition in developing zebra finch song nuclei are independent of auditory experience during song learning. J Neurobiol 22:215-223.

Cheng MF, Durand SE (2004) Song and the limbic brain: a new function for the bird's own song. Ann NY Acad Sci 1016:611-627.

Greenough WT, Black JE, Wallace CS (1987) Experience and brain development. Child Dev 58:539-559.

Harding CF (2004) Hormonal modulation of singing: hormonal modulation of the songbird brain and singing behavior. Ann NY Acad Sci 1016:524-539.

Jarvis ED, Nottebohm F (1997) Motor-driven gene expression. Proc Natl Acad Sci USA 94:4097-4102.

Konishi M (1963) The role of auditory feedback in the vocal behavior of the domestic fowl. Z Tierpsychol 20:349-367.

Konishi M (1965) The role of auditory feedback in the control of vocalization in the white-crowned sparrow. Z Tierpsychol 22:770-783.

Leuner B, Gould E, Shors TJ (2006) Is there a link between adult neurogenesis and learning? Hippocampus 16:216-224.

Li XC, Jarvis ED, Alvarez-Borda B, Lim DA, Nottebohm F (2000) A relationship between behavior, neurotrophin expression, and new neuron survival. Proc Natl Acad Sci USA 97:8584-8589.

Lombardino AJ, Nottebohm F (2000) Age at deafening affects the stability of learned song in adult male zebra finches. J Neurosci 20:5054-5064.
Mello CV, Vates GE, Okuhata S, Nottebohm F (1998) Descending auditory pathways in the adult male zebra finch (Taeniopygia guttata). J Comp Neurol 395:137-160.

Mello CV, Velho TA, Pinaud R (2004) Song-induced gene expression: a window on song auditory processing and perception. Ann NY Acad Sci 1016:263-281.

Ming GL, Song H (2005) Adult neurogenesis in the mammalian central nervous system. Annu Rev Neurosci 28:223-250.

Nordeen KW, Nordeen EJ (1992) Auditory feedback is necessary for the maintenance of stereotyped song in adult zebra finches. Behav Neural Biol 57:58-66.

Routtenberg A (1986) Synaptic plasticity and protein kinase C. Prog Brain Res 69:211-234.

Sakaguchi H, Yamaguchi A (1997) Early song-deprivation affects the expression of protein kinase $\mathrm{C}$ in the song control nuclei of the zebra finch during a sensitive period of song learning. NeuroReport 8:2645-2650.

Sakaguchi H, Wada K, Maekawa M, Watsuji T, Hagiwara M (1999) Songinduced phosphorylation of cAMP response element-binding protein in the songbird brain. J Neurosci 19:3973-3981.

Sartor JJ, Ball GF (2005) Social suppression of song is associated with a reduction in volume of a song-control nucleus in Eur starlings (Sturnus vulgaris). Behav Neurosci 119:233-244.

Sartor JJ, Charlier TD, Pytte CL, Ball GF (2002) Converging evidence that song performance modulates seasonal changes in the avian song control system. Soc Neurosci Abstr 28:781.10.

Smith GT, Brenowitz EA, Wingfield JC (1997) Roles of photoperiod and testosterone in seasonal plasticity of the avian song control system. J Neurobiol 32:426-442.

Theunissen FE, Amin N, Shaevitz SS, Woolley SM, Fremouw T, Hauber ME (2004) Song selectivity in the song system and in the auditory forebrain. Ann NY Acad Sci 1016:222-245.

Tramontin AD, Smith GT, Breuner CW, Brenowitz EA (1998) Seasonal plasticity and sexual dimorphism in the avian song control system: stereological measurement of neuron density and number. J Comp Neurol 396:186-192.

Tramontin AD, Hartman VN, Brenowitz EA (2000) Breeding conditions induce rapid and sequential growth in adult avian song control circuits: a model of seasonal plasticity in the brain. J Neurosci 20:854-861.

Tramontin AD, Perfito N, Wingfield JC, Brenowitz EA (2001) Seasonal growth of song control nuclei precedes seasonal reproductive development in wild adult song sparrows. Gen Comp Endocrinol 122:1-9.

Watanabe A, Kimura T, Sakaguchi H (2002) Expression of protein kinase C in song control nuclei of deafened adult male Bengalese finches. NeuroReport 13:127-132.

Wingfield J, Moore MC (1987) Hormonal, social and environmental factors in the reproductive biology of free-living male birds. In: Psychobiology of reproductive behavior: an evolutionary perspective (Crews D, ed), pp 149-175. Englewood Cliffs, NJ: Prentice Hall.

Wingfield JC, Farner DS (1978) The annual cycle of plasma irLH and steroid hormones in feral populations of the white-crowned sparrow, Zonotrichia leucophrys gambelii. Biol Reprod 19:1046-1056.

Woolley SM (2004) Auditory experience and adult song plasticity. Ann NY Acad Sci 1016:208-221.

Woolley SM, Rubel EW (1997) Bengalese finches Lonchura Striata domestica depend upon auditory feedback for the maintenance of adult song. J Neurosci 17:6380-6390.

Woolley SM, Rubel EW (1999) High-frequency auditory feedback is not required for adult song maintenance in Bengalese finches. J Neurosci 19:358-371.

Woolley SM, Rubel EW (2002) Vocal memory and learning in adult Bengalese finches with regenerated hair cells. J Neurosci 22:7774-7787. 